\title{
Concurrent gemcitabine and 3D radiotherapy in patients with stage III unresectable non-small cell lung cancer
}

Gerald SMA Kerner $^{1 *}$, Leon FA van Dullemen ${ }^{1}$, Erwin M Wiegman², Joachim Widder ${ }^{2}$, Edwin Blokzijl2 Ellen M Driever ${ }^{2}$, John WG van Putten ${ }^{3}$, Jeroen JW Liesker ${ }^{4}$, Tineke EJ Renkema ${ }^{5}$, Remge M Pieterman ${ }^{6}$, Marc JF Mertens ${ }^{7}$, Thijo JN Hiltermann ${ }^{1}$ and Harry JM Groen ${ }^{1}$

\begin{abstract}
Background: Stage III unresectable non-small cell lung cancer (NSCLC) is preferably treated with concurrent schedules of chemoradiotherapy, but none is clearly superior Gemcitabine is a radiosensitizing cytotoxic drug that has been studied in phase 1 and 2 studies in this setting. The aim of this study was to describe outcome and toxicity of low-dose weekly gemcitabine combined with concurrent 3-dimensional conformal radiotherapy (3D-CRT).

Patients \& methods: Treatment consisted of two cycles of a cisplatin and gemcitabine followed by weekly gemcitabine $300 \mathrm{mg} / \mathrm{m}^{2}$ during 5 weeks of 3D-CRT, 60 Gy in 5 weeks (hypofractionated-accelerated). Overall survival $(\mathrm{OS})$, progression-free survival (PFS), and treatment related toxicity according to Common Toxicity Criteria of Adverse Events (CTCAE) version 3.0 were assessed.

Results: Between February 2002 and August 2008, 318 patients were treated. Median age was 64 years (range 36-86); 72\% were male, WHO PS 0/1/2 was 44/53/3\%. Median PFS was 15.5 months ( $95 \%$ confidence interval [Cl], 12.9-18.1) and median OS was 24.6 months ( $95 \%$ Cl., 21.0-28.1). Main toxicity (CTCAE grade $\geq 3$ ) was dysphagia (12.6\%), esophagitis (9.6\%), followed by radiation pneumonitis (3.0\%). There were five treatment related deaths (1.6\%), two due to esophagitis and three due to radiation pneumonitis.
\end{abstract}

Conclusion: Concurrent low-dose gemcitabine and 3D-CRT provides a comparable survival and toxicity profile to other available treatment schemes for unresectable stage III.

Keywords: Gemcitabine, Stage III NSCLC, Radiotherapy, Concurrent chemoradiotherapy

\section{Introduction}

At presentation approximately $30 \%$ of patients with nonsmall-cell lung cancer (NSCLC) have locally advanced (stage III) disease [1]. Median overall survival for clinically staged NSCLC stage IIIA is 14 months and for stage IIIB 10 months with five-year survival of $19 \%$ and $7 \%$, respectively [2]. For good performance patients with unresectable stage III disease, the treatment of choice is concurrent chemoradiotherapy [3,4]. Different treatment

\footnotetext{
* Correspondence: g.s.m.a.kerner@umcg.nl

'University of Groningen and Department of Pulmonary Diseases, University Medical Center Groningen, Hanzeplein 1, P.O. Box 30.001, Groningen 9700 $\mathrm{RB}$, The Netherlands

Full list of author information is available at the end of the article
}

modalities are used in practice, but none is clearly superior to others [5-11].

Gemcitabine is among the strongest radiosensitizing drugs available, but its use in lung cancer has been limited due to substantial toxicity when combining fulldose gemcitabine with radiotherapy in treatment of stage III NSCLC $[12,13]$. Excess rates of radiation pneumonitis have been reported using gemcitabine in chemoradiation for lung cancer in earlier studies that had used 2D radiotherapy $[14,15]$. Previously, a phase I trial was conducted at our institution establishing a safe schedule of concurrent weekly $300 \mathrm{mg} / \mathrm{m}^{2}$ gemcitabine and 3D-CRT [16]. These results were confirmed in a phase II trial at our institution [17].

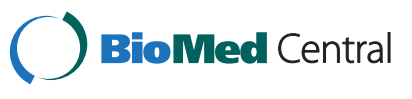


Here we report survival time and treatment related toxicity of this treatment regimen in a consecutive cohort of patients receiving gemcitabine-based concurrent chemoradiotherapy for stage III unresectable NSCLC over a period of 7 years. A subgroup analysis of patients aged $>70$ years was planned a priori.

\section{Materials and methods \\ Patient selection}

From February 2002 until December 2009, consecutive patients with stage III unresectable NSCLC who were treated with concurrent chemoradiotherapy with gemcitabine as radiosensitizer referred to one radiotherapy department from 6 hospitals in the northern part of the Netherlands were studied. Staging was performed by whole body ${ }^{18}$ F-FDG-PET, contrast enhanced chest CT, bronchoscopy, endoscopic ultrasound with fine-needle biopsy and mediastinoscopy. Treatment-related decisions were made during the weekly multidisciplinary meetings. The decision for treating these patients with this scheme, which was regarded as the standard treatment protocol for NSCLC stage III, was based on physical condition (performance status according to WHO), co-morbidity, and expected radiotherapy dose-volume constraints.

\section{Induction chemotherapy}

Chemotherapy consisted of two cycles of cisplatin $75 \mathrm{mg} / \mathrm{m}^{2}$ on day 1 and gemcitabine $1125 \mathrm{mg} / \mathrm{m}^{2}$ administered intravenously on day 1 and 8 of each 21-day cycle. This dose of gemcitabine provides the same dose intensity as the older 3 out of 4 week schedule. Antiemetics were ondansetron $8 \mathrm{mg}$ twice daily on days 1 and 2, and dexamethasone $8 \mathrm{mg}$ twice a day on days 1 and 2 of each cycle and aprepitant $125 \mathrm{mg}$ on day 1 and $80 \mathrm{mg}$ on days 2 and 3. The interval between the first dose of induction chemotherapy and the start of radiotherapy was 6 weeks.

\section{Radiotherapy with gemcitabine as sensitizer}

Patients received 3D-CRT to a total dose of 60 Gy, administered over 5 weeks in once daily fractions of $2.4 \mathrm{~Gy}$ five days per week, together with once weekly gemcitabine $300 \mathrm{mg} / \mathrm{m}^{2}$. Gemcitabine was omitted when leucocytes were below $3.10^{9} / \mathrm{L}$ or platelets below $100.10^{9} / \mathrm{L}$. The gross target volume (GTV) was delineated on the planning-CT and included the primary tumor and enlarged FDG-avid, or pathologically proven lymph nodes. Until 2005, tumor motion was determined with fluoroscopy and respective margins were added to the GTV, thereafter, an internal target volume (ITV) was individually delineated using a 4D-planning CT. A $5 \mathrm{~mm}$ margin was added to arrive at the clinical target volume, another $6 \mathrm{~mm}$ were added for the planning target volume (PTV). Radiotherapy was delivered using $6 \mathrm{MV}$ photons, the dose was specified at the isocenter and was corrected for pulmonary heterogeneity. The total radiation dose administered corresponded to an equivalent dose of $62 \mathrm{~Gy}$ if it were given in 2 Gy daily fractions.

\section{Dose constraints}

The spinal cord dose was constrained to 50 Gy. The mean lung dose (MLD) should not exceed 20 Gy (uncorrected for the slightly higher dose per fraction; this would equal 21.6 Gy converted to $2 \mathrm{~Gy} /$ fraction equivalent dose using an alpha/beta of 3Gy in the linear quadratic formula). The $V_{20}$ (the volume of the total lung volume receiving $\geq 20 \mathrm{~Gy}$ ) was constrained to $30 \%$ (this value is challenging to recalculate using the linearquadratic formula, but will correspond to a value about $8 \%$ higher if given in 2 Gy daily fractions).

For patients with high-volume disease, a proofplanning was made and evaluated for feasibility by the radiation oncologist. If necessary, the radiation dose was adapted. If the pulmonary dose constraints were still considerably exceeded after radiation dose reduction, patients were excluded from this protocol.

\section{Treatment evaluation}

Complete blood cell counts were performed on days 1 , 8 , and 22 of each induction chemotherapy cycle. On day 1 of each cycle, patient evaluation also included liver and renal functions, performance status, and toxicity scoring. During radiotherapy, complete blood cell counts and toxicity evaluation were performed. Two months after completion of treatment a response CT scan was obtained and patients were followed every 3 months with physical examination, laboratory tests and chest $\mathrm{x}$-ray. Disease progression was defined according to RECIST 1.0 criteria [18]. Toxicity (esophagitis, and radiation pneumonitis) related to treatment was retrospectively scored using the Common Toxicity Criteria (CTCAE 3.0) of the National Cancer Institute.

\section{Statistical analysis}

Descriptive statistics were used to characterize clinical features and toxicity. Using the Kaplan-Meier method, overall survival (OS) and progression-free survival (PFS) were calculated from the date of diagnosis until death, loss to follow-up, or first documentation of progressive disease, respectively. A subgroup analysis in patients aged over 70 years was performed to evaluate the outcome in elderly patients. Cox regression analysis was performed with the variables age, smoking, gender, histology, radiation dose, WHO performance score and PTV. A p-value of $<0.05$ was considered statistically significant. All calculations were performed using SPSS 20.0 (International Business Machines Corp, Armonk, NY, USA). 


\section{Results}

Three hundred and eighteen subsequent patients receiving concurrent chemoradiotherapy with gemcitabine as a radiosensitizer were studied. Median age was 64 years (range 36-86); male/female was 72/28\%; WHO PS 0/1/2 was 44,53 and $3 \%$. A total of 93 patients were aged $\geq 70$.

\section{Chemotherapy}

Two hundred and forty-two patients $(76 \%)$ received cisplatin and gemcitabine as induction, $42(13 \%)$ received carboplatin and gemcitabine, and 9 patients (3\%) received other schedules. Twenty five (8\%) patients did not receive induction chemotherapy. A total of $259 \mathrm{pa}$ tients $(81 \%)$ received all 5 weekly doses of gemcitabine during radiotherapy, 244 (76\%) received both full dose gemcitabine and full dose radiotherapy. Fifty-one patients (16\%) received between 1 and 4 gemcitabine administrations weekly, mainly due to neutropenia and thrombocytopenia. For the remaining 8 , no information was available. Patient characteristics are detailed in Table 1. Interestingly, advanced age did not lead to decreasing the concomitant gemcitabine dose (Table 2).

Seven patients $(2 \%)$ had a tumor resection after chemoradiotherapy.

\section{Radiotherapy}

The radiotherapy dose was 60 Gy in 284 patients (89\%) while less than $60 \mathrm{~Gy}$ (range, 29 to $58 \mathrm{~Gy}$ ) was administered in 34 patients (11\%). These 34 patients included 17 patients with increased risk of radiation pneumonitis due to increased $V_{20}$ and 8 patients who stopped treatment due to radiation related toxicity including $3 \mathrm{pa}$ tients with CTC grade 3 esophagitis. Nine patients received less than 60 Gy for undocumented reasons.

The median PTV was $431 \mathrm{cc}$ with the $90^{\text {th }}$ percentile at 734 cc. Median $V_{20}$ was $22.7 \%$ and the $90^{\text {th }}$ percentile was $31.0 \%$. In patients aged $\geq 70$, median PTV was not different at $411 \mathrm{cc}$ with the $90^{\text {th }}$ percentile at $702 \mathrm{cc}$. Median $\mathrm{V}_{20}$ was $23 \%$, with the $90^{\text {th }}$ percentile at $30.6 \%$.

\section{Survival}

Median PFS was 15.5 months (95\% CI., 12.9-18.1) (Figure 1a) and median OS was 24.6 months (95\% CI., 21.0-28.1) with a 5 -year survival of $26 \%$ (Figure 1b). In the 244 patients who completed full concurrent treatment, median survival was 26.3 months (95\% CI., 21.930.6 months) with a 5 -year survival of $27 \%$. In patients aged $\geq 70$, median PFS was 18.7 (95\% CI., 10.0-27.4) and OS was 26.2 months (95\% CI., 19.0-33.4) with a $19 \%$ 5 year survival rate.

Using univariate Cox analysis, current smoking at diagnosis, squamous cell histology, higher WHO performance score, male gender and larger PTV, were all identified as negative factors influencing survival. In
Table 1 Patient characteristics

\begin{tabular}{|c|c|c|}
\hline & Numbe & ents \\
\hline & $(N=318)$ & $\%$ \\
\hline Age & $64(36-86)$ & \\
\hline Male/Female ratio & $229 / 89$ & $72 / 28$ \\
\hline WHO 0 & 129 & 44 \\
\hline 1 & 151 & 53 \\
\hline 2 & 10 & 3 \\
\hline Unknown & 28 & \\
\hline Histology & & \\
\hline Adenocarcinoma & 68 & 21.4 \\
\hline Squamous cell & 157 & 49.4 \\
\hline NSCLC-NOS & 93 & 29.2 \\
\hline Smokers & & \\
\hline None & 9 & 3 \\
\hline Current & 163 & 51 \\
\hline Former & 109 & 34 \\
\hline Unknown & 37 & 12 \\
\hline Induction treatment & & \\
\hline Cisplatin/gemcitabine & 242 & 76 \\
\hline Carboplatin/gemcitabine & 42 & 13 \\
\hline Platinum/pemetrexed & 4 & 1 \\
\hline Other & 5 & 2 \\
\hline No induction & 25 & 8 \\
\hline Radiotherapy dose receive & & \\
\hline 30-59 Gy & 34 & 11 \\
\hline $60 \mathrm{~Gy}$ & 284 & 89 \\
\hline$>60 \mathrm{~Gy}$ & 0 & 0 \\
\hline During chemoradiotherap & & \\
\hline Received 5 gemcitabine $c$ & & \\
\hline and $60 \mathrm{~Gy}$ & 244 & 76 \\
\hline Received $1-4$ gemcitabine & & \\
\hline and/or received less & & \\
\hline then $60 \mathrm{~Gy}$ & 74 & 24 \\
\hline
\end{tabular}

Table 2 Number of cycles of weekly gemcitabine with respect to age in stage III NSCLC

\begin{tabular}{ccccccc}
\hline & \multicolumn{2}{c}{ Age $<\mathbf{7 0}$} & \multicolumn{2}{c}{ Age $\geq \mathbf{7 0}$} & \multicolumn{2}{c}{ Total } \\
\hline 1 & 1 & $(<1 \%)$ & 0 & & 1 & $(<1 \%)$ \\
2 & 7 & $(3 \%)$ & 3 & $(3 \%)$ & 10 & $(3 \%)$ \\
3 & 9 & $(4 \%)$ & 7 & $(8 \%)$ & 16 & $(5 \%)$ \\
4 & 13 & $(6 \%)$ & 11 & $(12 \%)$ & 24 & $(8 \%)$ \\
5 & 188 & $(84 \%)$ & 71 & $(76 \%)$ & 259 & $(84 \%)$ \\
\hline
\end{tabular}

From 8 patients the weekly gemcitabine dosage was not specified. 

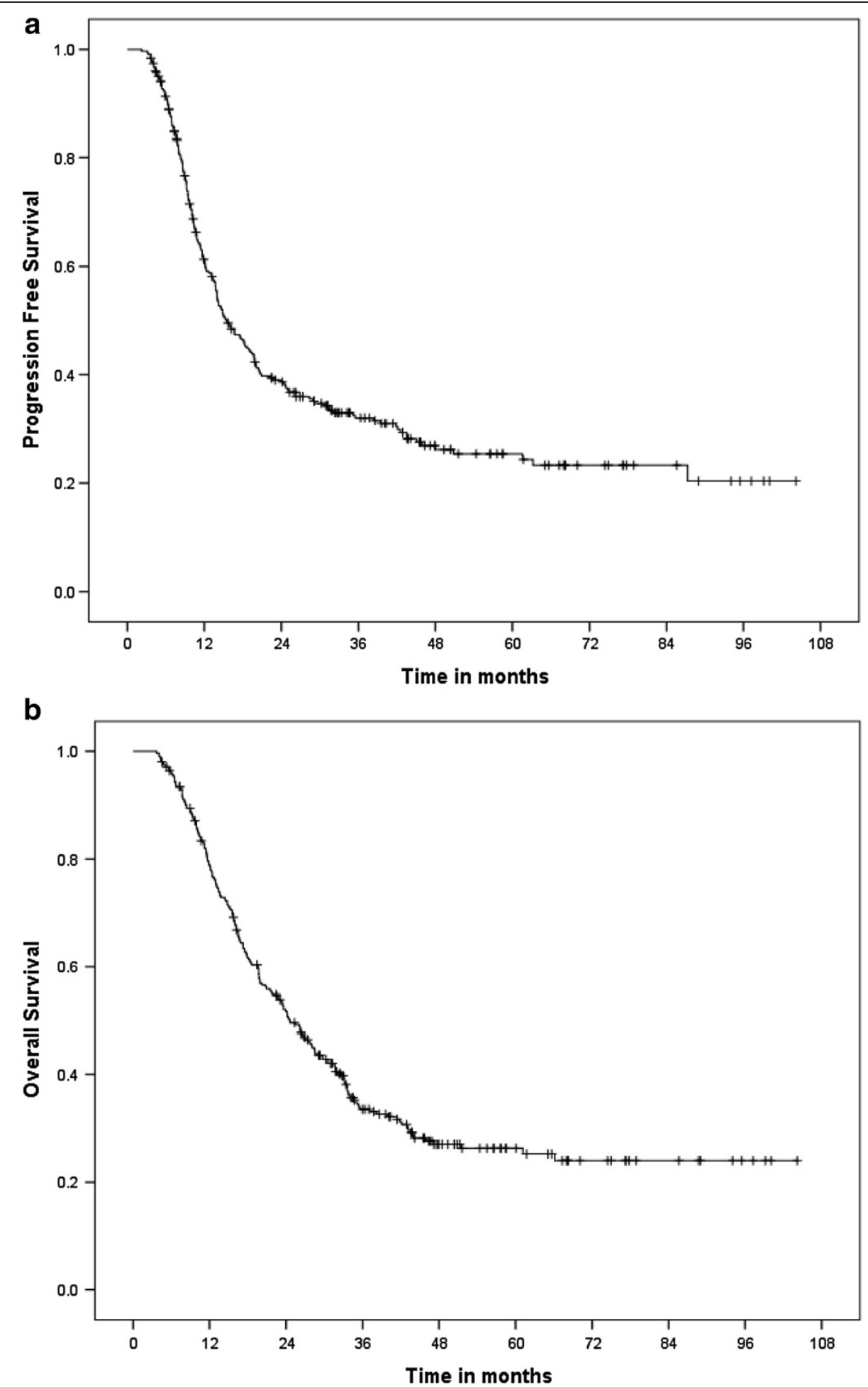

Figure 1 Survival of $\mathbf{3 1 8}$ patients treated with gemcitabine and 3D concurrent radiotherapy. a. Median Progression Free Survival was 15.5 months ( $95 \%$ Cl., 12.9-18.1). b. Median Overall Survival was 24.6 months ( $95 \%$ Cl., 21.0-28.1) with a 5-year survival of $26 \%$.

multivariate Cox analysis, current smoking, male gender and larger PTV remained as negative factors influencing survival.

\section{Toxicity}

Most common toxicities were CTC grade 2 esophagitis (13.6\%), and CTC grade 2 radiation pneumonitis (17.7\%) 
(Table 3). CTC grade $\geq 3$ esophagitis was seen in $9.7 \%$ with 2 CTC grade 5 events. One patient had an esophageal ulcerative stenosis which resulted in death due to a massive hemorrhage. The second patient received a stent for an esophageal stenosis. Later this patient developed an esophageal-bronchial fistula and died 22 months later. Three percent $(N=10)$ of the patients had CTC grade $\geq 3$ radiation pneumonitis. Three patients had a grade 5 event (all aged above 70 years). For these three patients, the PTV was 508, 600 and $578 \mathrm{cc}$ (the $75 \%$ percentile of the whole cohort was $576 \mathrm{cc}$ ), with a $\mathrm{V}_{20}$ of 16 , 34 , and $30 \%$, respectively. The first patient had no induction chemotherapy, the two others were treated with induction carboplatin and gemcitabine. In patients who completed the full chemoradiotherapy $(N=244), 7 \%$ had CTC grade $\geq 3$ esophagitis (including 1 CTC grade 5 event), and $4 \%$ CTC grade $\geq 3$ radiation pneumonitis (including 2 CTC grade 5 events). In patients aged 70 and older $(N=93), 9$ patients $(9.7 \%)$ had CTC grade 3 esophagitis, 4 patients (4.3\%) had CTC grade 3 radiation pneumonitis, and three patients (3.2\%) died due to pneumonitis. The other patients died due to progressive disease.

\section{Discussion}

In this paper, we described outcome and toxicity of weekly gemcitabine and 5 weeks of 3D-CRT for stage III NSCLC. The overall median survival was 24,6 months. Although comparisons between uncontrolled single institution series should be interpreted with great caution due to possible variation in patient selection criteria, in other concurrent chemoradiotherapy regimens median survival was between 15.3 and 26 months [5-10,19-21]. In addition, esophageal toxicity and radiation pneumonitis was also in the same range as other recent studies with concurrent chemoradiation [5-10,19-21].

Table 3 Radiation toxicity CTC $\geq 2$ in patients with stage III NSCLC treated with concurrent gemcitabine and 3D radiotherapy

\begin{tabular}{|c|c|c|c|c|c|c|}
\hline \multirow[t]{2}{*}{ Toxicity } & \multicolumn{2}{|c|}{ Total } & \multicolumn{2}{|c|}{ Age $<70$} & \multicolumn{2}{|c|}{ Age $\geq 70$} \\
\hline & $N=318$ & $\%$ & $\mathrm{~N}=225$ & $\%$ & $N=93$ & $\%$ \\
\hline \multicolumn{7}{|l|}{ Esophagitis } \\
\hline CTC 2 & 43 & 13.6 & 32 & 14.3 & 11 & 11.8 \\
\hline $\mathrm{CTC} 3$ & 29 & 9.1 & 20 & 8.9 & 9 & 9.7 \\
\hline CTC 4 & 1 & 0.3 & 1 & 0.4 & 0 & \\
\hline CTC 5 & 2 & 0.6 & 2 & 0.9 & 0 & \\
\hline \multicolumn{7}{|c|}{ Radiation pneumonitis } \\
\hline CTC 2 & 52 & 17.7 & 38 & 17.0 & 14 & 15.1 \\
\hline CTC 3 & 6 & 2.0 & 2 & 0.9 & 4 & 4.3 \\
\hline CTC 4 & 1 & 0.3 & 1 & 0.4 & 0 & \\
\hline CTC 5 & 3 & 0.9 & 0 & & 3 & 3.2 \\
\hline
\end{tabular}

In 2003 it had been shown that concurrent low-dose gemcitabine and 3D-CRT had acceptable toxicity [16]. Subsequently, a phase 2 study showed a median PFS of 12.4 months and OS of 21.6 months with acceptable toxicity [17]. This was the reason to adopt the here reported regimen as our protocol in the region, because we were unable to recognize excessive toxicity as reported by others, in our patients. For instance, in a study from Blanco et al., drug dosage was adapted due to toxicity while other studies have been closed due to unacceptable toxicity profiles (especially pulmonary toxicity) $[15,22,23]$. Price et al. investigated gemcitabine at a lower dosage $\left(100 \mathrm{mg} / \mathrm{m}^{2}\right)$ combined with a lower radiation dosage (55 Gy) given in a shorter time span (4 weeks) in a study that was prematurely closed due to slow accrual. There were 2 deaths in the gemcitabine arm due to acceleration of pre-existing interstitial lung disease [24]. Of note, in that study a daily fraction-dose of 2.75 Gy was given and the lung-dose-constraints had not been adapted for this higher dose per fraction. To our knowledge, there are no further reports using hypofractionated accelerated radiotherapy combined with gemcitabine.

The main factors that are important concerning pulmonary toxicity (i.e. radiation pneumonitis) during chemoradiation with concurrent low-dose gemcitabine are not completely understood. Lung dose, the use of conformal radiotherapy and the timing of the gemcitabine dosage are primary candidates. The CALGB 30105 trial showed that a $V_{20}$ of $40 \%$ was associated with significant grade 3-5 pulmonary toxicity [25], which would be expected with any other combination treatment, even with radiotherapy alone. We observed no unexpected pulmonary toxicity rates, because at our institute, the constraint for $V_{20}$ was set at a rather conservative $30 \%$ (uncorrected for the slightly higher daily fraction dose of 2.4 Gy) and indeed the vast majority (90\%) of treated patients had a $V_{20}$ lower than $30 \%$. Elective nodal irradiation was completely foregone in the first year of this study, with no ensuing statistically significant toxicity differences. However, all three patients in our study who died due to radiation pneumonitis were aged above $70-$ and had $V_{20}$ of 16,34 and $30 \%$, respectively. The CALGB study also identified older age to be associated with increased pulmonary toxicity [25].

Also for esophageal toxicity, radiation technique had been shown to be critical. In a phase 1 study, which initially started using 2D conformal techniques, but halfway switched to 3D techniques, the percentage of the esophagus irradiated to 60 Gy dropped from 68 to $18 \%$, and grade 2 esophagitis dropped from $5 / 10$ patients to 2/14 patients [14].

Administration of gemcitabine more frequently than once weekly was also associated with increased toxicity. 
One study administered gemcitabine twice weekly $\left(50 \mathrm{mg} / \mathrm{m}^{2}\right)$ with 3D radiotherapy with elective nodal irradiation of the mediastinum [22]. Of note, the PTV's in that study were three times as large as ours due to elective nodal irradiation. Due to unacceptable toxicity, the gemcitabine dose was reduced to $35 \mathrm{mg} / \mathrm{m}^{2}$, but even after this reduction, still more severe CTC grade $\geq 3$ esophageal and pulmonary toxicity was observed compared to our study. Our once weekly schedule featured 3 (for $50 \mathrm{mg} / \mathrm{m}^{2}$ ) to 4.3 times (for $35 \mathrm{mg} / \mathrm{m}^{2}$ ) the cumulative weekly gemcitabine dose [22]. This suggests that timing of drug administration may trigger toxicity, as was also demonstrated in our previous phase 1 and 2 clinical trials.

There were a total of 5 (1.6\%) non-hematological grade 5 events in our study, which is comparable to other mainstream treatment regimens $[6,7,10,20]$.

\section{Conclusions}

Treatment of patients with unresectable stage III NSCLC with cisplatin and gemcitabine followed by concurrent gemcitabine and 3D conformal radiotherapy was safe and yielded effectiveness and toxicity rates comparable with other drugs in our hands. These results are very likely due to conservative radiation dose-constraints and 3D-conformal radiotherapy avoiding irradiation of excessive volumes of uninvolved mediastinal areas. Although age was not a factor influencing survival and the absolute incidence at $3 \%$ grade 5 pneumonitis in patients older than 70 years was what could be expected, patients above 70 years of age should be selected with great caution for this regimen.

\section{Competing interest}

Through H.J.M.G, the hospital receives research grants from Eli Lilly, Pfizer and Roche. All remaining authors have declared no conflicts of interest.

\section{Authors' contribution}

Study concept and design was done by LFAD, EMW, TJNH and HJMG. Data acquisition was done by GSMAK, LFAD, EMW, JW, EB, EMD, JWGP, JJWL, TEJR, RMP, MJFM. Quality control and assurance was done by EMW, JW and EB. Data analysis, interpretation and statistical analysis was done by GSMAK, JW and HG. Manuscript preparation was done by GSMAK and HJMG. Editing and review was done by LFAD, EMW, JW, EB, EMD, JWGP, JJWL, TEJR, RMP, MJFM and TJNH. All authors attest to its validity and legitimacy of the presented facts and agree to its submission. All authors read and approved the final manuscript.

\section{Funding \\ This work was partly supported by CTMM, the Center for Translational Molecular Medicine, project AIRFORCE (grant 030-103). CTMM is a non- commercial entity that pays G.S.M.A.K his salary. CTMM did not play a role in the study design, in data collection, analysis and writing of the manuscript.}

\section{Author details}

${ }^{1}$ University of Groningen and Department of Pulmonary Diseases, University Medical Center Groningen, Hanzeplein 1, P.O. Box 30.001, Groningen 9700 $\mathrm{RB}$, The Netherlands. ${ }^{2}$ University of Groningen and Department of Radiation Oncology, University Medical Center Groningen, Groningen, The Netherlands. ${ }^{3}$ Martini Hospital, Groningen, The Netherlands. ${ }^{4}$ Scheper Hospital, Emmen, The Netherlands. ${ }^{5}$ Refaja Hospital, Stadskanaal, The Netherlands.
${ }^{6}$ Ommelander Hospital Group, Delfzijl, The Netherlands. ${ }^{7}$ Wilhelmina Hospital, Assen, The Netherlands.

Received: 22 March 2014 Accepted: 16 August 2014

Published: 29 August 2014

\section{References}

1. Mountain CF: Revisions in the international system for staging lung cancer. Chest 1997, 111:1710-1717.

2. Goldstraw P, Crowley J, Chansky K, Giroux DJ, Groome PA, Rami-Porta R, Postmus PE, Rusch V, Sobin L: The IASLC Lung Cancer Staging Project: proposals for the revision of the TNM stage groupings in the forthcoming (seventh) edition of the TNM Classification of malignant tumours. J Thorac Oncol 2007, 2:706-714.

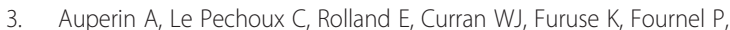
Belderbos J, Clamon G, Ulutin HC, Paulus R, Yamanaka T, Bozonnat MC, Uitterhoeve A, Wang X, Stewart L, Arriagada R, Burdett S, Pignon JP. Meta-analysis of concomitant versus sequential radiochemotherapy in locally advanced non-small-cell lung cancer. J Clin Oncol 2010, 28:2181-2190.

4. Vansteenkiste J, De Ruysscher D, Eberhardt WE, Lim E, Senan S, Felip E, Peters S: Early and locally advanced non-small-cell lung cancer (NSCLC): ESMO Clinical Practice Guidelines for diagnosis, treatment and follow-up. Ann Oncol 2013, 24(6):vi89-98.

5. Carter DL, Garfield D, Hathorn J, Mundis R, Boehm KA, llegbodu D, Asmar L, Reynolds C: A randomized phase III trial of combined paclitaxel, carboplatin, and radiation therapy followed by weekly paclitaxel or observation for patients with locally advanced inoperable non-small-cell lung cancer. Clin Lung Cancer 2012, 13:205-213.

6. Hanna N, Neubauer M, Yiannoutsos C, McGarry R, Arseneau J, Ansari R, Reynolds C, Govindan R, Melnyk A, Fisher W, Richards D, Bruetman D, Anderson T, Chowhan N, Chowhan N, Nattam S, Chowhan N, Nattam S, Mantravadi P, Johnson C, Breen T, White A, Einhorn L: Phase III study of cisplatin, etoposide, and concurrent chest radiation with or without consolidation docetaxel in patients with inoperable stage III non-smallcell lung cancer: the Hoosier Oncology Group and U.S. Oncology. J Clin Oncol 2008, 26:5755-5760.

7. Yamamoto N, Nakagawa K, Nishimura Y, Tsujino K, Satouchi M, Kudo S, Hida T, Kawahara M, Takeda K, Katakami N, Sawa T, Yokota S, Seto T, Imamura F, Saka H, Iwamoto Y, Semba H, Chiba Y, Uejima H, Fukuoka M: Phase III study comparing second- and third-generation regimens with concurrent thoracic radiotherapy in patients with unresectable stage III non-small-cell lung cancer: West Japan Thoracic Oncology Group WJTOG0105. J Clin Oncol 2010, 28:3739-3745.

8. Huber RM, Flentje M, Schmidt M, Pollinger B, Gosse H, Willner J, Ulm K: Simultaneous chemoradiotherapy compared with radiotherapy alone after induction chemotherapy in inoperable stage IIIA or IIIB non-smallcell lung cancer: study CTRT99/97 by the Bronchial Carcinoma Therapy Group. J Clin Oncol 2006, 24:4397-4404.

9. Gandara DR, Chansky K, Albain KS, Leigh BR, Gaspar LE, Lara PN Jr, Burris H, Gumerlock P, Kuebler JP, Bearden JD 3rd, Crowley J, Livingstone R: Consolidation docetaxel after concurrent chemoradiotherapy in stage IIIB non-small-cell lung cancer: phase II Southwest Oncology Group Study S9504. J Clin Oncol 2003, 21:2004-2010.

10. Gandara DR, Chansky K, Albain KS, Gaspar LE, Lara PN Jr, Kelly K, Crowley J, Livingston R: Long-term survival with concurrent chemoradiation therapy followed by consolidation docetaxel in stage IIIB non-small-cell lung cancer: a phase II Southwest Oncology Group Study (S9504). Clin Lung Cancer 2006, 8:116-121.

11. O'Rourke N, Roque IFM, Farre Bernado N, Macbeth F: Concurrent chemoradiotherapy in non-small cell lung cancer. Cochrane Database Syst Rev 2010, 6:CD002140.

12. Sandler A, Ettinger DS: Gemcitabine: single-agent and combination therapy in non-small cell lung cancer. Oncologist 1999, 4:241-251.

13. Scalliet P, Goor G, Galdermans D, van Meerbeek J, Groen HJM, Van der Leest AHW, Westerink H, Jungnelius U, Turrisi A: Gemcitabine with thoracic radiotherapy in chemonaive patients with advanced non-small-cell lung cancer. Proc Am Soc Clin Oncol 1998, 17:499.

14. Zinner RG, Komaki R, Cox JD, Glisson BS, Pisters KM, Herbst RS, Kies M, Liao Z, Hong WK, Fossella FV: Dose escalation of gemcitabine is possible with concurrent chest three-dimensional rather than two-dimensional 
radiotherapy: a phase I trial in patients with stage III non-small-cell lung cancer. Int I Radiat Oncol Biol Phys 2009, 73:119-127.

15. Arrieta O, Gallardo-Rincon D, Villarreal-Garza C, Michel RM, Astorga-Ramos AM, Martinez-Barrera L, de la Garza J: High frequency of radiation pneumonitis in patients with locally advanced non-small cell lung cancer treated with concurrent radiotherapy and gemcitabine after induction with gemcitabine and carboplatin. J Thorac Oncol 2009, 4:845-852.

16. van Putten JW, Price A, van der Leest AH, Gregor A, Little FA, Groen HJ: A Phase I study of gemcitabine with concurrent radiotherapy in stage III, locally advanced non-small cell lung cancer. Clin Cancer Res 2003, 9:2472-2477.

17. Wachters FM, van der Leest AHD, Klinkenberg TJ, Groen HJM: Treatment of unresectable locally advanced non-small-cell lung cancer with cisplatin and gemcitabine followed by concurrent radiation and gemcitabine. In Therapeutic strategies in advanced non-small-cell lung cancer. 1st edition. Haren: Drukkerij Van Ark; 2006:25-39. Wachters FM (Series Editor).

18. Therasse P, Arbuck SG, Eisenhauer EA, Wanders J, Kaplan RS, Rubinstein L, Verweij J, Van Glabbeke M, van Oosterom AT, Christian MC, Gwyther SG: New guidelines to evaluate the response to treatment in solid tumors. European Organization for Research and Treatment of Cancer, National Cancer Institute of the United States, National Cancer Institute of Canada. J Natl Cancer Inst 2000, 92:205-216.

19. Belderbos J, Uitterhoeve L, van Zandwijk N, Belderbos H, Rodrigus $P$, van de Vaart P, Price A, van Walree N, Legrand C, Dussenne S, Bartelink H, Giaccone G, Koning C: Randomised trial of sequential versus concurrent chemo-radiotherapy in patients with inoperable non-small cell lung cancer (EORTC 08972-22973). Eur J Cancer 2007, 43:114-121.

20. Curran WJ Jr, Paulus R, Langer CJ, Komaki R, Lee JS, Hauser S, Movsas B, Wasserman T, Rosenthal SA, Gore E, Machtay M, Sause W, Cox JD: Sequential vs Concurrent Chemoradiation for Stage III Non-Small Cell Lung Cancer: Randomized Phase III Trial RTOG 9410. J Natl Cancer Inst 2011, 103:1452-1460.

21. Hoang T, Dahlberg SE, Schiller JH, Mehta MP, Fitzgerald TJ, Belinsky SA, Johnson DH: Randomized phase III study of thoracic radiation in combination with paclitaxel and carboplatin with or without thalidomide in patients with stage III non-small-cell lung cancer: the ECOG 3598 study. J Clin Oncol 2012, 30:616-622.

22. Blanco R, Sole J, Montesinos J, Mesia C, Algara M, Terrassa J, Gay M, Domenech M, Bastus R, Bover I, Nogue M, Vadell C: Induction chemotherapy with cisplatin and gemcitabine followed by concurrent chemoradiation with twice-weekly gemcitabine in unresectable stage III non-small cell lung cancer: final results of a phase II study. Lung Cancer 2008, 62:62-71.

23. Choy H, Jain AK, Moughan J, Curran W, Whipple G, Demas WF, Ettinger DS: RTOG 0017: a phase I trial of concurrent gemcitabine/carboplatin or gemcitabine/paclitaxel and radiation therapy ("ping-pong trial") followed by adjuvant chemotherapy for patients with favorable prognosis inoperable stage IIIA/B non-small cell lung cancer. J Thorac Oncol 2009, 4:80-86.

24. Price A, Yellowlees A, Keerie C, Russell S, Faivre-Finn C, Gilligan D, Snee M, Skailes G, Hatton M, Erridge S, Mohammed N: Radical radiotherapy with or without gemcitabine in patients with early stage medically inoperable non-small cell lung cancer. Lung Cancer 2012, 77:532-536.

25. Salama JK, Stinchcombe TE, Gu L, Wang X, Morano K, Bogart JA, Crawford JC, Socinski MA, Blackstock AW, Vokes EE: Pulmonary toxicity in Stage III non-small cell lung cancer patients treated with high-dose (74 Gy) 3-dimensional conformal thoracic radiotherapy and concurrent chemotherapy following induction chemotherapy: a secondary analysis of Cancer and Leukemia Group B (CALGB) trial 30105. Int J Radiat Oncol Biol Phys 2011, 81:e269-274.

doi:10.1186/1748-717X-9-190

Cite this article as: Kerner et al:: Concurrent gemcitabine and 3D radiotherapy in patients with stage III unresectable non-small cell lung cancer. Radiation Oncology 2014 9:190.

\section{Submit your next manuscript to BioMed Central and take full advantage of:}

- Convenient online submission

- Thorough peer review

- No space constraints or color figure charges

- Immediate publication on acceptance

- Inclusion in PubMed, CAS, Scopus and Google Scholar

- Research which is freely available for redistribution

Submit your manuscript at www.biomedcentral.com/submit
() Biomed Central 